\title{
Technical and Organisational Changes in a Selected Production Process
}

\author{
Anna Rudawska ${ }^{1}$, Anna Flechsig ${ }^{1}$, and Izabela Miturska, ${ }^{1, *}$ \\ ${ }^{1}$ Lublin University of Technology, Faculty of Mechanical Engineering, Department of Production Engineering, Nadbystrzycka 36, \\ 20-618 Lublin
}

\begin{abstract}
Production is the most important and major activity of a production system. It may relate to goods used in various industries, as well as in agriculture or horticulture. The aim of this article is to analyse a selected production process and to propose several technical and organisational changes within the process of producing cucumbers in greenhouses in the form of a conceptual design. The scope of the article includes analysis and presentation of the current state of the selected production system, presentation of the modification project, as well as the possible impact of the proposed changes on the process under analysis. The subject of analysis herein is the greenhouse equipment, the production process organisation, technical facilities, production quality system functioning, proposition of changes and their effect on production. The analysis and modifications involved the production of cucumbers in greenhouses and their further preparation for sales, i.e. planting, harvesting, loading, segregating, weighing, packing and greenhouse liquidation. The article presents technical and organisational changes related with: the company's technological facilities, space organisation in the production hall, recordkeeping of hours worked, as well as the number of employees. The aforementioned modifications will effect in inter alia: reduced working time, elimination of redundant stoppages and modernisation of technological facilities.
\end{abstract}

\section{Introduction}

A proper choice of technological and organisational parameters of the production processes enables more efficient and effective production of goods. Production processes pertain to every industry, whether the mechanical, agricultural or food ones.

The subject of analysis herein is the greenhouse equipment, organisation, technical facilities, production quality system functioning, proposition of technical and organisational changes and their effect on production. The analysis and modifications concerned the process of production of cucumbers in greenhouses and their preparation for sale: planting, harvesting, loading, segregating, weighing, packing and greenhouse liquidation.

\section{Characteristics of the Company and the Current Process}

More and more vegetables present in the market are produced in greenhouses [1-4]. It allows for extending the growing season to a whole year round, hence enabling production for almost whole year. In addition, it boosts the profits of entrepreneurs and makes it easier to provide proper conditions for the obtaining of topquality products. In order to meet these expectations, it is necessary to improve the process organisation and to modernise technological facilities. A greenhouse design provides a continuous access to sunlight, which in turn ensures high and good-quality yields. The main problems of the currently constructed greenhouses are not related with thermal loss or the production process instability, but concern work organisation, as well as appropriate equipment and machines.

The production site under analysis consists of a production hall (approx. 0.25 ha) with three staff rooms, as well as sorting, packing and transporting areas. The production hall has a direct exit to the greenhouse (approx. 4 ha) through a tight sliding door that prevents thermal losses.

\subsection{Specification of the Cucumber Production Process}

In the analysed greenhouse, the season lasts from January 28th to December 18th. It includes two growth cycles of plants, each lasting five and a half months. During the first week (approx. 10 days before planting out) the heating system is turned on. Before the cultivation cycle starts, all the machines and devices are subject to inspection and disinfection. The greenhouse preparation begins with covering the ground with foil and conducting maintenance works on hooks and pipes supporting the construction. Then the synthetic soil mats are placed. They do not contain any mineral ingredients, which enables strict control of the medium distributed to plants. As the second step, the twines for attaching stems are hung up on the wires. The wires are located approx. 2 metres above the ground and go through the length of

\footnotetext{
*Corresponding author: i.miturska@pollub.pl
} 
one row. Every employee entering the hall takes about 200 jute twines and hangs them around their neck. Then wagons are brought about on the pipes in the rows and are used by employees hanging the twines for moving along. The distance between twines is about $1 \mathrm{~m}$. The order of hanging is very important, as twines in two neighbouring rows need to be tied alternately. If they are tied identically, cucumbers will not grow appropriately, the efficiency will be decreased and it will be much harder to harvest the plants. Grown leaves have a diameter of approx. $40-50 \mathrm{~cm}$. If stems are too close to each other, it is harder and more time-consuming to find the vegetables. When all of the above actions are completed, the 50-60 cm high cuttings in wool bricks are ordered. Every employee is provided with a trolley for transport crates, takes about 48 cuttings and is responsible for a particular row. Planting involves selection of the healthy seedlings, putting a healthy plant on the mineral mat and providing access to the sprinkling machine.

When planting is finished, the plants are watered and nourished with nutrients, depending on the growth rate and weather conditions.

Solution from the mat is sampled once or twice a week with use of a syringe. It is sampled in a few different spots and then subject to chemical analysis. The content of the components delivered to the plants is adjusted not only by the amount of solution, but also by change in the solution concentration (EC). It is obtained by changing the fertiliser dispenser setting. On sunny days, when the amount of fertiliser per plant is sufficient, the concentration needs to be decreased, whereas on cloudy days - increased [5-7].

The next step related to plant cultivation is referred to as wrapping. It is done twice or three times a week, depending on the weather conditions and growth rate. It consists in wrapping the plant's stem loosely with a twine that had been mounted on the wire beforehand. Wrapping technique and direction are of high importance - it cannot be too tight as the plant is not fully developed and fragile. Hence, it can break at the head and further growth will be impossible. Too loose wrapping, on the other hand, leads to the dropping of cucumbers and slower growth. In addition, the plant is prone to damage by trolley, sprayer or an employee. When there are 9 or more leaves developed on the main sprout, the 4th and the 8 th ones are removed (counting from the top). The following week the 3rd and 9th leaves are removed as well. During the next growth phase small cucumbers appear. Twice a week all the small side sprouts at the stem, flower buds and small cucumbers are being removed (apart from the two sprouts that are at the cucumber's head). It boosts the stem's growth rate. When the stem is about $2 \mathrm{~m}$ and side sprouts are $60 \mathrm{~cm}$ high, they are thrown over the wire. It is done by moving on trolleys with platforms. This activity is repeated the next week. At the same time, half of the main sprout is removed and the stem is mounted to the wire with a twine so that it does not fall under the cucumber weight. The harvest period starts from this moment on. Cucumbers are cut and sorted everyday depending on their weight. The cucumber classes are marked with colours and are classified according to the division presented in Table 1.

Table 1. Cucumber class depending on size.

\begin{tabular}{|c|c|c|}
\hline Class & Weight & Colour \\
\hline 1 & $400 \mathrm{~g}-450 \mathrm{~g}$ & White \\
\hline 2 & $380 \mathrm{~g}-400 \mathrm{~g}$ & Orange \\
\hline 3 & $>450 \mathrm{~g}$ & Blue \\
\hline 4 & $280 \mathrm{~g}-380 \mathrm{~g}$ & Red \\
\hline
\end{tabular}

Cucumbers are divided during picking by employees, who estimate their weight based on visual appearance. After that the cucumbers are placed on the scales located at the main passage in the greenhouse - shown in Fig. 1.

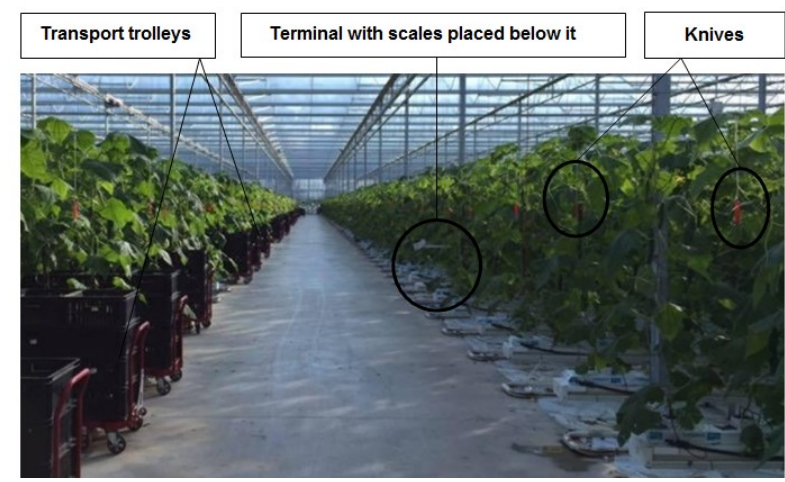

Fig. 1. The main passage in the greenhouse.

Desired length of a cucumber is from $18 \mathrm{~cm}$ to 26 $\mathrm{cm}$, diameter approx. $4 \mathrm{~cm}$. The colour should be darkgreen and desired skin in shiny and slightly ribbed.

After the main growth phase, when all the fruits are ripe, the plants die and are liquidated (usually in the first half of July). The greenhouse and machines are subject to disinfection again, and the equipment and working clothes are replaced. That marks the starting point of the second cycle, which lasts until the end of December.

\subsection{The Greenhouse Equipment}

When cultivating plants in a greenhouse, it is of high importance to provide them with proper growth conditions, which will in turn lead to good-quality products. It is necessary to install necessary devices and control system, which ensure appropriate temperature, humidity, carbon dioxide content in the air, light intensity and water content in soil [8]. As the aforementioned conditions vary, depending on the plants' growth phase, the parameters are not fixed. Cucumbers may be cultivated in high foil tunnels, even span or contiguous greenhouses. The process under analysis takes places in a contiguous greenhouse equipped with a modern heating system. It consists of three cycles: basic (at the walls), additional (in the heating pipes at the soil) and the third one (at the soil, next to the plants). In addition, in order to prevent from thermal losses, the greenhouse is equipped with shade screens unrolled above the plants, surface heating systems, fans distributing heat and covers of the side walls made of air cushion foil [5]. There are three independent production control systems in the greenhouse. The growth conditions are controlled by a 
control system equipped with a climate computer. It gathers information from sensors placed both inside and outside the building. Subsequently, the data is processed and the computer alters the soil temperature and air humidity, as well as manages roof ventilation, shade screens and heating control. The climate computer enables graphic representation of the climate changes and recording and archiving the machines operation state. In the case of an emergency failure, an authorised employee receives a text message, which enables taking immediate reaction. Cucumbers have significant demand for water, which necessitates the installation of a sprinkling machine. The second system is responsible for watering and providing plants with proper amount of fertilisers. What is more, plants, depending on the growth phase, are provided with adequate amounts of $\mathrm{CO}_{2}$ and growth medium [7, 9-10].

The greenhouse is equipped with a plants fastening construction. The cucumbers planted in such mats grow along the twines fastened to the wires attached to the greenhouse construction.

Every employee has a waterproof watch with a chip. It is connected with the third system, which manages production. Every time an employee enters the site they put the watch against the reader and logs into the system. Working time is counted automatically. There are 9 readers on site: one at the entrance and 8 more between the rows with cucumbers. At the entrance the employees need to come close to the reader and press the button reading "start work", from when the duration of the first activity is counted. The last activity is also the end of the working day. After the activity is finished the employee needs to put the chip against the reader, type the number of activity and the row that was involved in it. The exception is cutting the cucumbers: in this case it is also necessary to type in the trolley number and the number of crates. This particular instance of automatisation improves the work quality, as a result, the employees' efficiency is improved and reaction to their mistakes is immediate.

During the greenhouse preparation, harvest and segregation, all the employees must obey by the health and hygiene rules. They include:

- up-to-date medical records,

- positive epidemiological-sanitary opinion,

- clean working clothes,

- personal hygiene, e.g. washing hands often,

- protecting cuts with the use of a waterproof bandages.

\subsection{Working time records during harvest}

The harvest is usually once every two days, when the cucumbers are mature enough for consumption. In the morning all employees meet in the production hall next to the entrance to the greenhouse. The foreman passes on the quality requirements and gives instruction related with the size of cucumbers. If it is at the beginning of the season, class 1 and 2 cucumbers are cut. If there is a high demand for the product, the price of the orange class is high as well. In the middle of the season the white class products are the most desirable as their price is the highest. On very sunny days, when cucumbers grow faster than usually (20 g - $30 \mathrm{~g}$ daily), the orange class fruits are also cut in order to prevent them from overgrowing.

The foreman also informs if the nurturing needs to be carried out that day. The nurture day means that after the harvest is finished, there will be a need to carry out other activities, such as:

- cleaning the stem from the redundant blastema,

- cutting the sprouts,

- cutting off the leaves blocking the sunlight,

- hanging sachets with spiders in order to eliminate pests,

- removing overgrown cucumbers from the bottom parts of the stem.

After having familiarised with the requirements, every employee enters the greenhouse, logs into system, takes a trolley with transport crates and a knife. Dedicated knives are hanged at the entrance to the row. After having finished the harvest on one side, an employee comes to the reader and provides the information. Work starts and 6:30 am. Breaks are announced by a signal from the speaker at 9 am (the 15minute long breakfast break) and at 12 o'clock (the 30minute long lunch break). On hot days or when there are lots of cucumbers, there is an additional 15-minute break and 3:30 pm. All activities performed by the employees are processed by the system. Reports are being continuously updated.

\subsection{Current Production Process Scheme and Description}

Currently the production hall consists of one main and two additional rooms. The working area includes:

- area for empty trolleys,

- area for empty and full pallets,

- area for full trolleys standing in the line to the sorting machine,

- sorting machine.

- area for manual sorting of cucumbers that will be sold to the micro-enterprises,

- wrapping machine,

- area for waste.

Current product organisation scheme is presented in Fig. 2.

1 - empty trolleys are taken by the employees from the storage area (B) and transported to the greenhouse (J),

2 - full trolleys are taken by the foreman from the greenhouse to the area $(\mathrm{F})$ and crates with cucumbers are passed for retail to the sorting area $(\mathrm{H})$,

3 - cucumbers are transported to the sorting machine $(\mathrm{G})$ by the machine operator,

4 - the crates are loaded on the pallets by the employees operating the sorting machine and wrapped by the foreman,

5 - the pallets are transported by the foreman to any empty spot in the area for placing pallets (E) and marked with bar codes.

6 - empty trolleys are returned by the foreman to the primary place $(\mathrm{B})$,

7 - pallets are transported to a lorry by an employee responsible for delivery reception. 


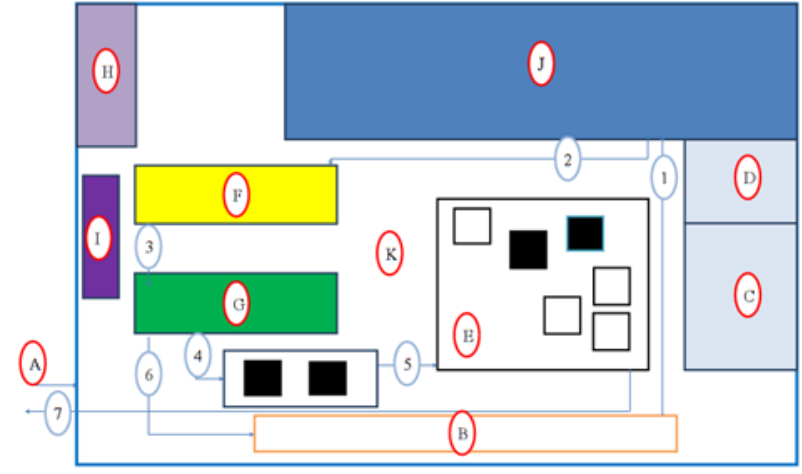

Fig. 2. Current product organisation scheme:

A - entrance door to the production hall,

B - area for empty trolleys,

C - staff room,

D - sanitary room,

E - area for empty and full pallets,

F - area for full trolleys lined up to the sorting machine,

$\mathrm{G}$ - sorting machine,

$\mathrm{H}$ - the area for manual sorting of cucumbers for retail,

I - crates with sorted cucumbers unfit for consumption and waste area,

$\mathrm{J}$ - greenhouse,

$\mathrm{K}$ - production hall,

L - wrapping machine.

\section{Proposed technical and organisational changes in the production process}

The proposed scope of changes is expected to improve the enterprise development; they are aimed at:

- improving the product quality,

- improving work efficiency,

- reducing working hours during the day,

- modernising the technological facilities.

\subsection{The Concept of Changes}

\subsubsection{Replacement of crates in the transport trolleys}

The currently used crates cannot be stacked. When picking cucumbers, an employee who is at the end of the row has to rearrange the crates in such a way as to have free space for more cucumbers. It causes unnecessary stoppages and prolongs the operation realisation time. It often happens that empty crates that are in use fall off the trolleys, which causes additional breaks in harvesting as employees waste time on arranging them and become distracted - which may lead to leaving grown cucumbers. Ripe cucumbers left on the stem may overgrow by the next harvest, which will generate financial losses. The selection of stackable crates on the market is huge. Fig. 3 presents the comparison of crates most popular with producers of vegetables.
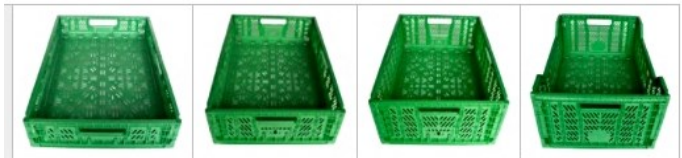

Fig. 3. Comparison of stacking crates available on the market.

The range of operating temperatures is between $-40^{\circ}$ to $+50^{\circ} \mathrm{C}$, and they come in the following colours: white, grey and green. Their solid construction, meshed bottom and sides allow the movement of air, thanks to which the products will remain fresh longer [11-12]. Made of highdensity polyethylene (HDPE) crates ensure safety, solid construction and long-term use. The cost of one crate, depending on the size and the order size is on average PLN 20, PLN 25, PLN 34 and PLN 43.

From both economic and ergonomic point of view, the most profitable crates are in the following dimensions: $600 \mathrm{~mm}$ x $400 \mathrm{~mm}$ x $200 \mathrm{~mm}$. The load weight is $20 \mathrm{~kg}$, which allows for storing maximum 44 white class cucumbers. One EURO pallet holds 48 unfolded crates. One transport holds 33 pallets, so the number of crates needed for one full transport is 48 pcs $* 33=1,584$ pcs. Total cost of investment in the new crates amounts to 1,584 pcs * PLN $34=$ PLN 53,856.

\subsubsection{Spatial organisation on the production hall}

In order to shorten the working time and to improve effectiveness it is necessary to reorganise physical resources in the production hall. Changes are presented in Fig. 4 (designations in accordance with Fig. 2). In the original version, the area for pallets was located next to the entrance to the greenhouse - it has been moved closer to the entrance to the production hall. Moreover, it has been divided into two parts; the first one will serve as an area for empty pallets (designated with an empty square) and full pallets ready for transport (designated with a filled square). The area for empty trolleys has been expanded. The area for manual sorting of cucumbers for retail and waste has also been changed. Another modification was to equip the production hall with the machine that packs cucumbers in foil before they are sorted and sent.

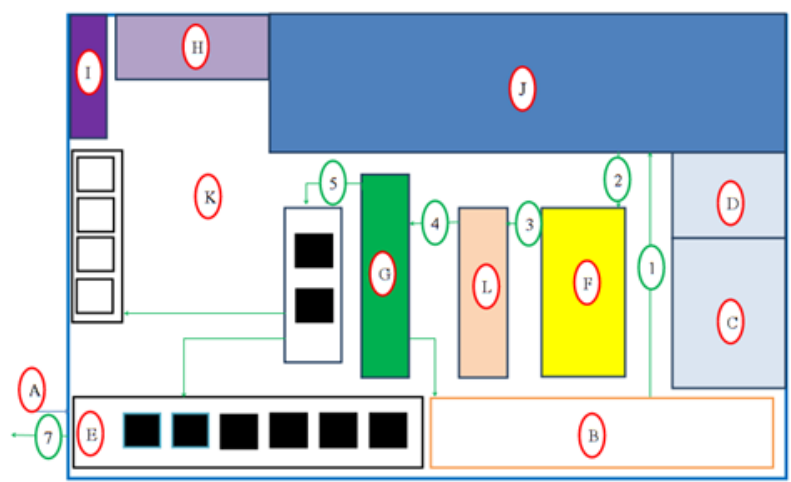

Fig. 4. Modified production organisation scheme.

Among all the wrapping machines for food industry that are available on the market, there are only two that meet the requirements for packing cucumbers in greenhouses. The first one, produced by Christiaens, ensures long freshness of vegetables thanks to tight package in foil that prevents loss of moisture. This device costs approx. PLN 175,000. The most important advantages of the Christiaens CS01 wrapping machine are the following:

- adjustable wrapping speed,

- maximum packing capacity - up to 5200 pes in 60 minutes, 
- single knife system enabling economical use of foil.

Another proposed machine is Scorpion E Flow Pack Machine. Its price on the secondary market amounts to PLN 60,000. The machine wraps vegetables in a transparent film. Its dimensions are rigorously defined; maximum width must be $160 \mathrm{~mm}$ and maximum height $70 \mathrm{~mm}$.

Taking the above into consideration, the Christiaens CS01 wrapping machine, presented in Fig. 5, will be the best choice. Its biggest advantage is adjustable wrapping speed, which impacts accuracy of the whole operation.

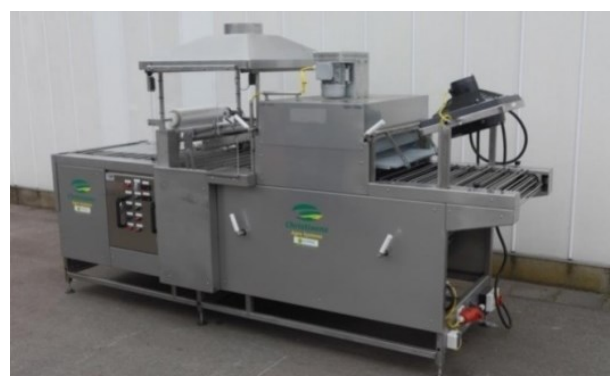

Fig. 5. Christiaens CS01 wrapping machine [13].

Thanks to innovative technology, cucumbers are thoroughly wrapped which prolongs their freshness and allows ensuring the highest quality standards. Foil protects cucumbers from mechanical damage, dirt and impact of external factors, such as: dry air in transport or long waiting for delivery in unfavourable weather conditions. Moreover, the single knife system enables reducing the use of foil, whereas advanced software makes wrapping faster and more efficient.

\subsubsection{Working time and the number of employees}

Another proposition is to change the record keeping of hours worked and the way of logging into the system. Currently every employee has to leave the row after finishing one activity in order to put their chip against the reader to $\log$ in. It would be much more comfortable to equip the employees with portable terminals that would allow them to record the finished activities without the need to cover long distances in the greenhouse.

Among the terminals available on the market, the best choice for the process described above would be Cipherlab CPY $8000 \mathrm{~L}$ presented in the Fig. 6.

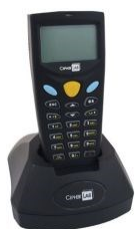

Fig. 6. Cipherlab CPY 8000 L [14].

It is powered with alkaline batteries, whose life amounts up to 100 hours. Thanks to small dimensions (122 $\mathrm{mm} \times 56 \mathrm{~mm} \times 26 \mathrm{~mm}$ ) this terminal is ergonomic, and its LCD display ensures great visibility even on sunny days. Moreover, among all the analysed terminals, the one described above has the best shock resistance and works properly even in the case of falling down from $1.2 \mathrm{~m}$. It is also equipped with a laser diode and 21 backlit keys, for scanning bar codes and works thanks to the in-built software based on C and BASIC compilers and Application Generator. One device costs PLN 2,000. In the process under analysis the number of employees varies between 20 to 40, depending on the season. Hence, the maximum cost of investment amounts to PLN 80,000.

Another proposition is to hire two additional employees. As the foreman has too many duties, he is not able to fulfil all of them without delays. One position should involve the whole work with transporting empty trolleys to the greenhouse and the full ones to the wrapping machine. The second position would be limited to operating the wrapping machine, labelling and transporting pallets in the hall. Employment Agreement Costs for the employer with the gross monthly salary PLN 3,700 amounts to PLN 4,462.57.

\subsection{Cost Analysis of the Proposed Changes}

Table 2 shows the analysis of expenses related with the planned investments by determining a type of the planned investment, demand, unit cost and total cost.

Table 2. Analysis of expenses generated by the proposed changes.

\begin{tabular}{|c|c|c|c|}
\hline Investment type & Demand & $\begin{array}{c}\text { Price } \\
{[\mathrm{PLN}]}\end{array}$ & Cost [PLN] \\
\hline New crates & $1,584 \mathrm{pcs}$ & 34 & 53,856 \\
\hline $\begin{array}{c}\text { Christiaens CS01 } \\
\text { Wrapping Machine }\end{array}$ & $1 \mathrm{pc}$. & 175,000 & 175,000 \\
\hline $\begin{array}{c}\text { New portable } \\
\text { terminals }\end{array}$ & $40 \mathrm{pcs}$ & 2,000 & 80,000 \\
\hline $\begin{array}{c}\text { Job positions } \\
\text { for 12 months }\end{array}$ & $\begin{array}{c}2 \\
\text { employee } \\
\text { s }\end{array}$ & $53,550.84$ & $107,101.68$ \\
\cline { 2 - 5 } & \multicolumn{2}{|c|}{ Total cost } & $415,957.68$ \\
\hline
\end{tabular}

Cucumbers are picked 64 times during the season. During one day from May to September, the number of picked cucumbers is equal to one full lorry load, i.e. 1,584 crates. As one crate can hold 44 cucumbers maximum, the number of cucumbers picked during one day is 69,696 maximum. An average price of cucumber is PLN 2.5. Daily income from sales of cucumbers in this period is PLN 209,088. At the assumed harvest realisation, invariable product price, and considering fixed costs, such as employee remuneration, power, heating, water and fuel, the cost of investment pays off within one month.

\section{Summary}

Although the production site is equipped with modern devices for sorting cucumbers and transporting pallets, it is still necessary to hire more employees and to improve quality of end products.

The present article describes technical and organisational changes in the production process of cucumbers: 
1) replacement of transport crates to stackable crates. The construction of crates with meshed bottom and sides enables airflow, which guarantees the highest-quality standards. The proposed solution also impacts the work ergonomics and eliminates stoppages related to rearranging crates; hence shortening a working day. This investment improves work efficiency, shortens the harvesting time and reduces the storage area in the production hall. Its cost amounts to PLN 53,856.

2) reorganisation of physical resources in the production hall and investment in the wrapping machine. Arranging space for empty and full pallets, as well as expanding the area for empty trolleys eliminates chaos that was there before modifications. Changes in the workspace organisation improve work speed, eliminate undesirable stoppages caused by lack of space or situations when an employee collecting the pallets needs to wait until the foreman moves away other pallets to gain access to the product. Moreover, the system facilitates labelling full pallets with bar codes. Proper space arrangement makes it easier for an employee responsible for coding to find a specific pallet among dozen other ones. In order to modernise technological facilities, we propose the purchase of a wrapping machine - Christiaens CS01 for PLN 175,000. Thanks to that cucumbers will stay fresh for longer and will be better protected from mechanical damage while sorting, packing or transporting.

3) change of record keeping of hours worked, which is connected with investment in modern portable terminals Cipherlab CPY 8000 L. It can contribute to shortening the working time and to improving the work comfort. It will reduce the time that an employee needs to come up to the stationary terminal located at the main entrance in order to $\log$ in to the system and mark completion of an activity, as they will be able to do this directly from the place they are working at the given moment. The software used in the device enables assigning statuses to particular activities, such as "pending" by means of bar codes. This not only enables controlling the production system in real time, but also allows for immediate reaction to production errors, e.g. when one employee picks the cucumbers of a wrong class. Cost of investment in new terminals amounts to PLN 80,000.

4) hiring two new employees. One position would involve delivering empty trolleys to the greenhouse and transporting the full trolleys to the wrapping machine. The second position would focus on operating the wrapping machine and transporting pallets to the specified places in the hall and designating them with bar codes. The gross monthly cost of Employment Agreements for two employees amounts to PLN $8,925.14$

Dynamic development of technology opens the possibilities for the introduction of innovative solutions that effect in:
- improving the product quality,

- improving the production processes,

- meeting the requirements of the most demanding customers.

The analysis of the cucumber production process in the greenhouse has resulted in determining a number of potential investments. If all the assumptions are fulfilled, the total cost of buying new crates, devices and employing new people will amount to PLN 415,957.68.

\section{References}

1. F. L. Li, W. Shi, Z. F. Jin, H. M. Wu, G. D. Sheng, J Geochem Explor., 173, 76-84 (2017)

2. G. Dosi, R. Nelson, S. Winter, The nature and dynamics of organizational capabilities (OUP Oxford, 2001)

3. J. Bijman, Towards New Rules For The EU's Fruit And Vegetables Sector. An EU Northern Member States Perspective. Europees Parlement, DirectorateGeneral for Internal Policies; Policy Department B; Structural and Cohesion Policies; Agriculture and Rural Development (2015)

4. M. Li, S. Chen, F. Liu, L. Zhao, Q. Xue, H. Wang, J. F. Bienvenido, PRECIS AGRIC, 18, 6 (2017)

5. F. Adamicki, B. Nawrocka, Metodyka integrowanej produkcji ogórków pod ostonami (Warszawa, 2014)

6. M. Omid, F. Ghojabeige, M. Delshad, H. Ahmadi, H., ENERG CONVERS MANAGE, 52, 1 (2011)

7. S. H. Pishgar-Komleh, M. Omid, M. D. Heidari,. Energy, 59, 63-71, (2013)

8. K. Rutkowski, Inżynieria Rolnicza 6, 315-321 (2009)

9. M. Omid, A. Akram, R. Pahlavan, Application of Data Envelopment Analysis for Performance Assessment and Energy Efficiency Improvement Opportunities in Greenhouses Cucumber Production (2018)

10. M. Omid, F. Ghojabeige, M. Delshad, H. Ahmadi, ENERG CONVERS MANAGE, 52, 153-162 (2011)

11. M. Chadrzynski, Economic Science for Rural Development Conference Proceedings, 32 (2013)

12. A. Mohammadi, M. Omid, Appl Energy, 87, 1 (2010)

13. https://www.duijndammachines.com/pl/maszyny/1434/christiaens-nowaogórek-uszczelniaczem-kurczą-otoki-cs01/, data dostępu 17.01.2018.

14. https://dymicom.pl/pl/p/Kolektor-danych-CipherlabCPT-8000-L-CPT8001 